\title{
Entre la defensa y la intervención social: Estado, ciudadanía y pobreza en la ciudad de Concepción (Chile, 1890-1930)*
}

\author{
por \\ Marco León León y Mauricio Rojas Gómez \\ Universidad del Bío Bío/Universidad de Concepción \\ mleon@ubiobio.cl/mrojas@ubiobio.cl
}

Esta investigación busca entender al Estado chileno desde una triple dimensión: regional, relacional y constructiva; lo cual permite visualizar en un caso específico lla ciudad de Concepción) y en un tiempo determinado (el período 1890-1930), las particularidades de un modelo estatal no bien estudiado: el de Defensa Social, que presenta variaciones respecto de su antecedente decimonónico, el Estado Guardián, y de su sucesor natural: el Estado Benefactor. Las características y manifestaciones normativas e institucionales de dicho modelo, a nuestro entender, son evidenciables tanto en el área de salubridad mental y en el manicomio, como también en la función de vigilancia y protección que comienzan a desarrollar de manera complementaria la Intendencia, la Policía de Seguridad y la Oficina del Trabajo.

PalabRas Clave: estado; ciudadania; pobreza; exclusión; defensa social; intervención social.

\section{INTRODUCCIÓN: ESTADO E HISTORIOGRAFÍA CHILENA}

Los estudios sobre el Estado en Chile han sido bastante significativos a lo largo de su historia republicana, pero fue durante el siglo XX que se ensayaron las interpretaciones más influyentes sobre la historia del mismo ${ }^{1}$, concibiéndolo como algo más que una serie de gobiernos o instituciones polí-

* Este artículo se ha elaborado en el marco del proyecto de Investigación 2011-2014, “Del «ser moral» a la conversión en «ser político». Estado, sociedad y construcción de ciudadanía en Concepción y Talcahuano (1860-1925)", financiado por el Fondo Nacional de Desarrollo Científico y Tecnológico, FONDECYT (Chile), Referencia nº 1110842.

${ }^{1}$ Edwards, 1928. Góngora, 1981. 
ticas relacionadas y jerarquizadas, sino más bien como una abstracción dotada de un espíritu propio y omnipresente en la evolución del país. Si bien dicha postura encontró matices y críticas en las investigaciones de historiadores de tendencia liberal o marxista ${ }^{2}$; otros investigadores, sin caer en esencialismos, determinismos o marxismos, entendieron para fines de los años sesenta al Estado como una compleja estructura administrativa, carente de alma, pero no de un cuerpo, representado por un cada vez más creciente aparato administrativo ${ }^{3}$.

A fines de la década de 1980 y principios de la siguiente, gracias también al avance de los procesos democratizadores, la manera en que comenzó a replantearse el estudio del Estado llevó a que éste fuese considerado no sólo como un espíritu o cuerpo administrativo, sino fundamentalmente como un constructo, entendiéndose así que la vida política, social, económica y cultural era una construcción de los individuos y no algo «dado» o definible sólo desde el poder de turno ${ }^{4}$. De ahí el interés por investigar y reinterpretar su carácter multidimensional y ponderar el papel de la sociedad civil, no sólo de las autoridades, en la preservación del orden político y social ${ }^{5}$. En dicho escenario intelectual empezó la redefinición de conceptos como los de ciudadanía, nación, patria y representación política, entre otros. Tal viraje epistemológico y metodológico al momento de estudiar al Estado, sus relaciones con la sociedad civil, los procesos de institucionalización de lo social y sus representaciones culturales, también fue incorporado y desarrollado por la historiografía chilena desde los noventa en adelante ${ }^{6}$.

Muchos de los estudios existentes sobre el Estado chileno utilizan diversas caracterizaciones para referirse a él (Liberal, Gendarme, Guardián, Benefactor, Asistencial, de Compromiso o Empresarial) ${ }^{7}$, aunque son pocos los que entran a definirlas y explicarlas. En tal sentido, el Estado Liberal-Guardián del siglo XIX ha sido conceptualizado a partir del control que ejercía el poder político para garantizar el funcionamiento del contrato social, como nueva forma de legitimación respecto del Antiguo Régimen. Los derechos de libertad e igualdad se volvían fundamentales en él, aunque éstos debían funcionar dentro de la competencia del mercado, debiendo así crearse un límite en la actividad estatal, no regulándose la economía, sino sólo la seguridad del orden interno y externo del territorio. De ahí su papel de Gendarme o Guardián y la necesidad,

2 Feliú Cruz, 1951. Jobet, 1951.

3 Urzúa, 1970. Urzúa y García, 1971.

4 Bravo Lira, 1984; 1985.

5 Jocelyn-Holt, 1997. Salazar, 2005.

${ }^{6}$ Fernández, 2003. Jocelyn-Holt, 1997. Illanes, 1993. Salazar y Pinto, 1999. Yáñez, 2008.

7 Barros y Vergara, 1991. Cavarozzi, 1978. Ibáñez, 1996. Illanes, 1993. Massardo, 2004. Salazar y Pinto, 1999. Villalobos, 1988. 
como parte de una economía capitalista, de velar para que se interiorizara una disciplina de trabajo, elemento fundamental del sistema y bien valioso que concurría a esta lógica de mercado ${ }^{8}$.

La historiografía chilena del Estado, independiente del contexto en que haya surgido, y de admitir matices, contradicciones y ambigüedades interpretativas, ha tendido a enfatizar una evolución lineal de los modelos estatales ${ }^{9}$. Por ello, sigue manteniéndose dentro de este esquema interpretativo la idea de un paso casi natural y mecánico desde un Estado Guardián decimonónico hacia uno Asistencialista durante el período 1891-1930, etapa marcada además en Chile por fenómenos históricos paralelos como la consolidación del régimen parlamentario, la mayor visualización de una «cuestión social», la modernización industrial y urbana, la participación de los militares como actores políticos y la promulgación de una nueva carta constitucional en 1925. El período, y su agitado desenvolvimiento, de acuerdo con las visiones existentes, sentaría las bases de un nuevo modelo benefactor o asistencialista, marcado ahora por un papel más protagónico del Estado en el área económica y social, con mayor preocupación por los derechos de los trabajadores y la creación de políticas públicas destinadas a evitar los conflictos entre el capital y el trabajo ${ }^{10}$.

Otro aspecto visible, sin restar los méritos particulares, es el hecho de que a pesar de los progresos investigativos al momento de concebir la actividad estatal, los estudios siguen manteniendo un carácter centralista en el análisis, omitiendo las características regionales y provinciales, con muy raras excepciones y circunscritas más bien a las primeras décadas pos independentistas ${ }^{11}$. Se sabe poco sobre cómo el Estado y sus representantes funcionaron fuera de Santiago y Valparaíso (el puerto principal del país), ciudades que han concentrado los estudios de los historiadores y de otros estudiosos. De ahí la necesidad de rescatar el proceso de construcción estatal desde un punto de vista regional y local, y no sólo con generalizaciones, lo que permite, a nuestro modo de ver, comprender los diferentes ritmos y apropiaciones que tienen los procesos por las autoridades y la sociedad civil. Es en dicha línea de trabajo que buscamos acercarnos al Estado desde una perspectiva distinta y en un período específico, entendiéndolo a partir de una perspectiva regional, relacional y constructiva. Regional porque se concentra en Concepción, la ciudad capital de la provincia del mismo nombre, la cual no ha merecido

${ }^{8}$ Bustos Ramírez, 1983: 16-18.

9 Barros y Vergara, 1991. Castedo, 1999

${ }^{10}$ Fernández, 2003. Illanes, 1993. Mac Clure, 2012. Massardo, 2004. Salazar y Pinto, 1999. Tuozzo, 2004. Yáñez, 2008.

11 Salazar, 2005. 
mayores estudios desde el punto de vista del Estado y sus vínculos con la sociedad civil urbana y popular. Relacional, porque buscamos rescatar las características multidimensionales de los modelos de Estado existentes y ver su real vigencia en la ciudad en estudio. Y constructiva, porque más que una abstracción, el Estado toma significado y significante en las múltiples relaciones establecidas entre autoridades, instituciones, medidas, ideas, leyes y reacciones por parte de la población.

\section{¿DÓNDE ESTÁ EL ESTADO? LAS INVESTIGACIONES SOBRE LA REALIDAD URBANA Y POPULAR EN CONCEPCIÓN}

Las interpretaciones más atingentes sobre la importancia del período 18911925, como las de Fernández y Tuozzo, y la redefinición que allí presentan de la relación entre el Estado y la sociedad civil, fundada hasta entonces en la exclusión, apuntan a destacar un punto de inflexión a partir de 1924, fecha desde la cual

...hay un desbordamiento de la realidad oligárquica por las dinámicas de otros sectores sociales que terminan con el monopolio que los grupos oligárquicos tenían del Estado y disuelven la matriz excluyente sobre la que éste operaba ${ }^{12}$.

Tal conclusión puede tener sentido, como hemos expuesto, si se observa desde Santiago, pero en la ciudad de Concepción, ubicada en la zona centro-sur de Chile, un cambio notorio en las relaciones sociales no fue perceptible sólo desde esa fecha. Si se revisan las investigaciones existentes que dicen relación con las condiciones laborales y de vida de los sectores populares en dicha urbe, en el período indicado, es notorio encontrar constantes referencias no sólo a un contexto de modernización industrial y comercial ${ }^{13}$, de crecimiento urbano ${ }^{14}$, o de problemas entre las autoridades, los trabajadores y los marginales; sino además a que la ausencia de la autoridad estatal es evidente al momento de constatar las carencias en vivienda, salud, educación, servicios urbanos y trabajo ${ }^{15}$. Para estos estudios, el Estado sólo se haría presente en la zona después de la crisis de 1929, durante las décadas de 1930 y 1940 con los planes de industrialización y de intervención efectiva en el área económica y social ${ }^{16}$.

\footnotetext{
${ }^{12}$ Fernández, 2003: 11. En el mismo sentido Tuozzo, 2004: 65.

13 Mazzei, 1991.

14 Alarcón y Pedreros, 1989. Hernández, 1983: 47-70.

15 Benedetti, 2010. Hernández y Torres, 1992. Inostroza y Tapia, 1993.

${ }^{16}$ Gacitúa y Vergara, 2000. Inostroza, 1999.
} 
A nuestro entender, es preciso matizar y comprender que el Estado no estuvo ausente por completo en el período de cambio de siglo (1890-1930), pues en primer término se hizo presente, aunque fuese por medio de su cara más negativa, a través de la represión a cualquier acción que alterara la convivencia social, construida por los grupos dirigentes, dado que «hacia el resto de la población sólo existió una proyección de las visiones que las oligarquías tenían de la realidad» ${ }^{17}$. Igualmente, es difícil concebir que pudiese existir una relación de carácter asistencial o de bienestar con la población cuando tal criterio no estaba establecido ni era una exigencia fiscalizada por nadie. Lo que es más, basta recordar que la protección social no era entendida aún como un «derecho», sino como un «favor». Por ello, sólo algunas dimensiones del Estado eran visibles, entre ellas las prácticas políticas, administrativas y legales que, por supuesto, todavía no iban en una dirección destinada a institucionalizar lo social. Para fines del siglo XIX y principios del siglo XX, no sólo en Concepción, sino también en otras áreas de Chile, ya se apreciaba un cuestionamiento a la naturalización del mundo social oligárquico y excluyente que se había conformado durante el siglo $\mathrm{XIX}^{18}$. Desde el punto de vista de las autoridades y las elites dirigentes, el «pueblo» en toda su diversidad (desde obreros hasta marginales), irrumpía en una realidad que no se quería compartir. Por ello, las huelgas, manifestaciones, meetings, y otras muestras del movimiento obrero local ${ }^{19}$, eran interpretadas como transgresiones al orden público.

De acuerdo con lo anterior, sostenemos que el problema de considerar la ausencia del Estado dentro de la provincia, y de la ciudad en particular, ha radicado en pedirle a dicho Estado una serie de características que aún no se generalizaban y que no definían su función principal. De hecho, es posible observar que aún pasada la década de 1920 el Estado seguía manteniendo muchos rasgos propios de su etapa de Guardián, pero no observamos en la zona en estudio un tránsito inmediato o mecánico a su nuevo rol Asistencial, lo cual se debe a que las investigaciones citadas le piden o asignan al Estado de entonces una función que aún no madura ni interioriza. Más que sólo constatar tal situación, creemos que lo que se manifiesta en el período en estudio en Concepción es un Estado de Defensa Social (Bustos Ramírez) o Policial (Tuozzo), antes que sólo Guardián o Benefactor. La diferencia estriba en que mientras en su rol de Guardián el Estado reacciona a través de la acción directa, como antes se expresó, en un Estado de Defensa Social, que guarda igual muchas características similares con la fase anterior, lo que define su

\footnotetext{
${ }^{17}$ Fernández, 2003: 65.

18 Benedetti, 2010.

19 Vivallos y Brito, 2008.
} 
accionar es «la prevención, la vigilancia de los sospechosos y la protección de los ciudadanos»». Tal Estado también es excluyente, aunque se basa sobre premisas distintas: las de bienestar y orden, «dejando en claro que el bienestar se alza como el objetivo de la policía y el orden, como su herramienta ${ }^{20}$. Por ello, desde 1924 lo que se evidencia es una centralización progresiva de funciones estatales de control y vigilancia, así se explica que ese mismo año, por un decreto ley, se unifiquen en el país los cuerpos de policía existentes (orden, seguridad e identificación), pasando de la esfera municipal a la del gobierno central, «cuya presencia y poder fueron afirmados y legitimados por la Constitución de $1925 »^{21}$.

Es a través del cuerpo policial (seguridad e identificación), y de instituciones similares de orden penal y mental, que se vigila y protege. ¿A quién se vigila? A quienes se encuentran determinados social y genéticamente, por su vulnerabilidad, para atentar contra la vida y las propiedades del grupo social dominante (los protegidos). Son los sectores populares, catalogados a partir de una ilegalidad intrínseca que refuerza los prejuicios existentes y que encuentra desde fines del siglo XIX respaldo científico en las ideas positivistas, en especial en aquellas relacionadas con el determinismo biológico y las teorías de la degeneración racial y social; los principales sospechosos. Aquí es donde aparece en sus primeros perfiles la noción de un «individuo peligroso», ante el cual se deben tomar medidas preventivas. Asimismo, se entrelazan las lógicas de un Estado de Defensa Social con uno Asistencial (este último interpretado, aunque en otros términos, por Illanes ${ }^{22}$, pues al momento de identificarse a prostitutas, enfermos mentales, alcohólicos, mendigos, delincuentes y, en general, a los «peligrosos»; los representantes estatales y sus instituciones, en su afán de disciplinar y cumplir dicha función de defensa social, terminarán ensayando las categorías y razones que justificarán la intervención estatal en la vida de los pobres. Para autores como Salvatore y Sozzo $^{23}$, éste sería incluso el legado del positivismo criminológico, en boga durante el período aquí abordado.

Dicha interpretación, creemos, puede ser matizada y aplicada a la ciudad de Concepción, y a sus habitantes, durante las primeras décadas del siglo XX, precisamente para tratar de desentrañar las prácticas políticas, administrativas y legales que permitan comprender la naturaleza de este Estado de Defensa Social, cuyo problema fundamental

\footnotetext{
20 Tuozzo, 2004: 31.

${ }^{21}$ Ibidem: 65.

22 Illanes, 1993: 15.

23 Salvatore y Sozzo, 2009: 22.
} 
...será legitimar la intervención en la libertad e igualdad de los individuos para someterlos al «bien social», para clasificarlos conforme a ello en peligrosos y no peligrosos, en anormales y normales ${ }^{24}$.

\section{ESTADO, POBREZA Y PELIGROSIDAD EN CONCEPCIÓN}

En el escenario urbano de Concepción de principios del XX, es posible apreciar los resultados de la evolución demográfica, industrial, social y económica que paulatinamente están modificando su condición fronteriza desde mediados de la centuria anterior ${ }^{25}$. Las transformaciones que se han operado en la ciudad y su sociedad han vuelto más complejo el tema de la vigilancia y resguardo de los intereses de la clase propietaria, aparte de aumentar la densidad poblacional de la periferia que va concentrado ahora a la población proletaria que gira en torno a las industrias y servicios, aparte de la población marginal ya existente. Es hacia dicho sector popular que se dirigen las medidas destinadas a evitar posibles desórdenes y muestras de descontento, de lo cual dan fe las numerosas tentativas por parte de la policía de seguridad y sus reglamentaciones ${ }^{26}$, encaminadas a mantener la disciplina sobre una población pobre estigmatizada desde antaño, pero que desde la década de 1880 había visto una redefinición del papel tutelar y represivo de las autoridades locales y nacionales gracias a la influencia del positivismo, como antes se expresó, que había ido brindando al Estado, o a sus representantes, la legitimación para la intervención, pues en la ciencia, que trazaba los límites entre lo normal y lo anormal, lo correcto e incorrecto, lo inofensivo y peligroso; se buscaba el fundamento del orden social, la disciplina y la organización. Sería dicha legitimación científico-positiva, el soporte ideológico de un nuevo Estado Defensor.

Entendemos que analizar cómo se establece la relación entre Estado y pobreza es clave dentro de este proceso de construcción de un Estado de Defensa Social. En dicha línea, queda claro que para las autoridades y las elites de Concepción la pobreza es entendida más como una situación (de la cual se culpa a los propios pobres) que como una relación, pues ello implicaría aceptar las desigualdades políticas sociales y económicas que definían la carencia de cosas, relaciones y la portación de otras. Frente a la pobreza, y los pobres -en su diversidad-, no se tenía una política clara, en la medida que no se entendía como una obligación, aunque existía algo semejante a un

\footnotetext{
${ }^{24}$ Bustos Ramírez, 1983: 18.

${ }^{25}$ Hernández, 1983. Pinto, 2003. León León, 2003; 2015.

${ }^{26}$ Código de Policía local para la comuna de Concepción..., 1915.
} 
consenso moral, un punto de vista común que prevalecía en la formulación de una incipiente política social. Tal es el caso de la ley de habitaciones obreras (1906), que se convirtió en un fracaso en la realidad urbana de nuestra ciudad en estudio, por el desconocimiento que se tenía no sólo de las características de la ciudad, sino también de la vida y costumbres de sus habitantes populares $^{27}$, muestra asimismo de la falta de una cultura asistencial estatal, la que trató de ser suplida o complementada, según el caso, por la filantropía y la beneficencia, en la medida que se creía que el pobre, vigilado y controlado, sólo tenía derecho a la protección ${ }^{28}$, pero no a la participación social o política. Por ende, al pobre peligroso (en acción o en potencia) había que controlarlo; al pobre menesteroso, había que protegerlo, pero nada más. Tal era la relación que se iba construyendo entre el Estado y los sectores populares penquistas, la cual admitió matices y voces disonantes, pero que no cambiaron el escenario discursivo entregado por la Intendencia, la policía local o la prensa en toda su variedad ideológica (desde la más conservadora hasta la más progresista).

Otra relación establecida fue entre la pobreza y la peligrosidad, amparada en el positivismo en su versión criminológica, que reafirmará que los vicios y pecados atribuibles a los sectores populares sólo serán la consecuencia, no la causa, de una cadena hereditaria de primitivismos que determinarán una peligrosidad explícita o virtual, capaz de surgir en el momento más inesperado, afectando el orden y la seguridad de los ciudadanos. De ahí el temor ante la degeneración física y mental que se advertía en Concepción, como planteaba el doctor Carlos Ugalde en 1911, al referirse a los sectores populares:

Entre las causas de la mortalidad infantil, tenemos el alcoholismo y la sífilis hereditaria, la mayoría de los niños afectados hereditariamente mueren durante la maternidad y los que sobreviven son organismos mui debilitados en que fácilmente prenden las enfermedades contajiosas. Hai entre estos niños algunos epilépticos, escrofulosos, paralíticos i muchísimos atacados de afecciones mentales; todos estos son un ejército de dejenerados $i$ una verdadera carga social ${ }^{29}$.

La peligrosidad aparecerá como una cualidad latente que requiere prevención por parte de quienes resguardan la propiedad pública y privada, todo ello reforzado por un discurso médico-higienista que insistirá en la

27 Alarcón y Pedreros, 1989: 159-166.

${ }_{28}$ Universidad de Concepción, Sala Chile (UDEC, SCh), Junta de Beneficencia de Concepción, vols. 4 5, 6, 7 y 8; con abundantes referencias sobre este particular.

29 "La hijiene en Concepción", El Sur, Concepción, 31 de julio de 1911. La cursiva es nuestra. 
degeneración racial ${ }^{30}$. Al momento de establecer la peligrosidad como una categoría, se obviarán las distinciones entre obreros, marginales, anarquistas, hombres, mujeres, niños y ancianos; organizándose una «penalidad centrada en lo que se es» ${ }^{31}$, preocupada más del criminal que del crimen: «noción extendida a una amplia gama de anomalías sociales e individuales que suponen un «peligro» para la sociedad. Bajo la doctrina de la defensa social, el Estado arrestará en forma preventiva a individuos que no habían cometido delito alguno, por considerarlos propensos a delinquir» ${ }^{32}$. Por ende, «ya no se plantea el grado de responsabilidad de los individuos, sino su peligrosidad». El discurso de las autoridades de la Intendencia y de la Policía en Concepción, es bastante explícito en los primeros años del siglo XX sobre este punto, reiterándose y reafirmándose ideas que circularon de seguro a nivel nacional y que encontraron también acogida en la realidad local aquí examinada ${ }^{33}$.

¿Cuáles fueron las prácticas políticas, administrativas y legales de este Estado Interventor? No siempre es fácil poder distinguirlas, pues tienden a entrelazarse, pero ayudan a entender la lógica de dominación construida sobre el criterio de la exclusión. En lo político, se aprecia una «ciudadanía» construida con tal carácter exclusivo y excluyente, cuya naturaleza es de corte civil y política, relativa a los derechos necesarios para la libertad individual (expresión, pensamiento y religión, propiedad) y a la participación en el ejercicio del poder político, pero no social, es decir, vinculada a entender la seguridad y un mínimo de bienestar económico como un derecho ${ }^{34}$. Esto se refleja administrativamente en que las instituciones existentes o creadas a nivel nacional, pero que tomaron dimensión local, como la Intendencia y la Oficina del Trabajo (1907); si bien a medida que avanzó el período mostraron una mayor preocupación social, ello fue de la mano con la necesidad de identificar y vigilar a una población que les era desconocida por no haber sido integrada antes. En el caso puntual de la policía, ocurrió algo similar, en especial cuando quedó claro para mediados de la década de 1920, que dicho cuerpo armado no era capaz de ser sostenido por el poder local y fue retomado por el control del Estado, quien buscó centralizar y modernizar a las policías: Carabineros en 1927 e Investigaciones en 1933. La legislación del período, refleja lo indicado:

\footnotetext{
${ }^{30}$ Fernández Labbé, 2009: 17-40.

31 Foucault, 2006: 176.

32 Salvatore y Sozzo, 2009: 21.

33 Aqueveque, 1920. Benítez, 1919. Espejo, 1915. Marshall, 1917.

34 Marshall y Bottomore, 1998.
} 
un interés social progresivo por los más pobres que va de la mano con su necesaria identificación y vigilancia ${ }^{35}$.

En términos gruesos, tales prácticas evidenciaron distintos desplazamientos respecto de cómo se entendía el resguardo de los intereses de los propietarios en el Estado Guardián, por lo cual hubo más preocupación en este Estado Defensor por el criminal antes que por el crimen; por el peligro virtual o en potencia antes que por el acto cometido; por la protección de los otros antes que por el castigo del culpable; dejando así establecida a la «sospecha» como un concepto clave en esta nueva manera de entender la relación entre el Estado y la sociedad civil-popular penquista. Frente a ello, «la protección y la vigilancia» cobraron relevancia. La primera, porque se dirigía a lo que no se podía controlar, a lo que se temía, a lo que podía atacar en cualquier momento (el individuo peligroso). La segunda, porque apuntaba a una función estatal que se hacía más explícita. Si el Estado se encargaba de la ley y el orden, haciendo uso de la fuerza para proteger a los ciudadanos, también podía utilizarla para vigilar al resto de los habitantes.

\section{SALUBRIDAD E INSTITUCIONALIDAD MENTAL}

Dentro de la lógica del Estado Guardián y de su sucesor, el Estado de Defensa Social, la salud de la población era vista como algo que desbordaba sus atribuciones y el socorro organizado como atentatorio contra el libre juego de las leyes del mercado. De acuerdo con la caracterización general de René Salinas: «La idea más común de la salud era la de una atención individual. Sólo el interés individual se consideraba suficiente. En otras palabras, la suma de intereses individuales debía dar como resultado el bienestar de la comunidad» ${ }^{36}$. Institucionalmente, la salud estuvo a cargo de las Juntas de Beneficencia, creada la primera de ellas en Santiago en 1833 y replicada luego en otros lugares del país. Hasta mediados de ese siglo, la presencia estatal en materias de salud, o salubridad que era el término más frecuente en diversas publicaciones, era, como se comprenderá, poco relevante ${ }^{37}$, pues en términos gruesos se pensaba que era tarea propia de los particulares y de la Iglesia. Sólo indirectamente, o en ocasiones específicas, como durante las epidemias,

35 Poblete y Álvarez, 1924. La legislación de identificación y vigilancia como el DecretoLey del 8 de septiembre de 1924, del 7 y la circular del 21 de octubre del mismo año, se encuentra en Tuozzo, 2004: 34-61.

${ }^{36}$ Salinas, 1983: 103.

${ }^{37}$ Molina, 2010. 
se pensaba que el Estado debía cobrar cierto protagonismo. No obstante ser ese el panorama generalizado, es posible observar una excepción a esta regla, visible en el caso de la salubridad mental y, en concreto, en las instituciones dedicadas a los enfermos mentales.

Hasta fines de la centuria decimonónica, la Casa de Orates de Santiago era la institución que cumplía la función de asilar a los enajenados del país ${ }^{38}$, pero al culminar el siglo estaba claro que se requería de un nuevo lugar que pudiese cumplir el mismo papel en el sur de Chile. Dicha preocupación, fue evidente en las autoridades estatales, pues a través del Ministerio del Interior y de las Juntas de Beneficencia se buscaron opciones en ciudades como Talca, Chillán y Concepción; siendo favorecida la última por presentar las mejores condiciones sanitarias. Tal interés del Estado respondía a una progresiva preocupación por las temáticas sanitarias que se habían traducido en distintas medidas institucionales (Junta Central de Vacuna y Junta General de Salubridad en 1887, Consejo Superior de Higiene Pública en 1889) y legislativas (Ley Orgánica de Higiene Pública en 1892) de alcance nacional; las cuales constituían respuestas al problema coyuntural que significaba la amenaza de enfermedades infecciosas que tomaban rasgos epidémicos entre la población.

La historia y trayectoria del manicomio en Concepción ha sido analizada recientemente en un interesante trabajo ${ }^{39}$, por lo cual sólo destacaremos algunos acontecimientos que ayudan a entender la función que dicho establecimiento tendrá en la ciudad. Como se planteó, se eligió a Concepción por la «uniformidad de su clima, la proximidad del mar» y por «la facilidad de comunicación i de traslacion que por tierra i por mar ofrece», según lo indicaba el informe presentado al Ministerio del Interior por el doctor Manuel Beca en $1894^{40}$. Al año siguiente, se concretó la compra del edificio que ocupaba la congregación del Buen Pastor para establecer allí las dependencias del nuevo manicomio que comenzó sus funciones en octubre de 1895. El manicomio fue entregado, de acuerdo con la instrucción del Ministerio del Interior, «a la vigilancia i dirección de la Junta de Beneficencia» de la ciudad, dentro de la cual ya se apreciaba la participación de médicos y la inclusión de sus criterios en varias decisiones ${ }^{41}$. En una primera etapa (1895-1922), la institución funcionó con algunos altibajos de organización y presupuesto, pero como se estableció que debía hacerse cargo de los enfermos mentales desde la ciudad de Talca hasta Puerto Montt, no fue

38 Camus, 1993: 89-140.

39 Sievers, 2013.

${ }^{40}$ Archivo Nacional de Chile, Santiago de Chile, (ANCh), Ministerio del Interior, vol. 1978, s.f.

${ }^{41}$ UDEC, SCh, Junta de Beneficencia de Concepción, vols. 4 y 5. 
sorpresa que con el paso de años se encontrara sobrepoblado. Para 1922, logró concretarse un nuevo traslado al ahora denominado Manicomio Avello, ubicado en la periferia de Concepción, y que respondía a una iniciativa respaldada tanto por la ciencia médica como por la Junta de Beneficencia, el Ministerio del Interior y el Congreso Nacional. El nuevo manicomio tomaba su nombre de José Cardenio Avello, millonario y filántropo que había legado su fortuna a las Juntas de Beneficencia de Concepción, Santa Juana y al Obispado de Concepción. Esta segunda etapa (1922-1929), finalizaría con el cierre y venta del manicomio al Ministerio de Guerra, tanto por las presiones ejercidas desde el Ejército como por el propio Ministerio ${ }^{42}$.

¿Cuál fue el rol del Estado en el manicomio de la ciudad? ¿Qué lo hizo diferente? Como se puede apreciar por lo explicado, el Estado tuvo directo interés tanto en la creación y organización del manicomio en Santiago como en las dos etapas del de Concepción. Dicho interés respondía al hecho de que se requerían establecimientos especializados en el tratamiento o internación (transitoria o permanente) de la locura, ello porque la presencia del loco en los espacios públicos, en especial de quienes no tenían los medios económicos ni a familiares para asistirlos, comenzó desde temprano a verse como un peligro para el orden social que la autoridad estatal deseaba consolidar en el país. En tal sentido, la Casa de Orates de Santiago se volvió insuficiente y de allí surgió la iniciativa de crear un nuevo establecimiento que ayudara con esta tarea al de Santiago, pero desde la capital los criterios en un principio fueron que el manicomio en Concepción tuviese un carácter provisorio y que estuviese destinado exclusivamente a los enfermos incurables o dementes. En el primer caso, ello se pensaba porque la idea era construir un nuevo manicomio nacional que reemplazara a la Casa de Orates en Santiago, el que concentraría a la población insana del país que pudiese tener una cura. Así, el manicomio en Concepción fue visto como una alternativa mientras culminaba el nuevo manicomio en Santiago.

Para las autoridades de un estado centralizado y centralista, la mantención del orden moral y social de la población requería contar con espacios de intervención -o instituciones- para los criminales y locos, ideas reforzadas desde las décadas finales del siglo XIX. Hasta entonces, el asilo era concebido por el Estado como una institución de beneficencia, por ende, de carácter hospitalario-asistencial, ahí radicaba el hecho de que fuese el Ministerio del Interior y no el de Justicia el que velase por su correcto funcionamiento. Mediante el tratamiento se buscaba establecer en los asilos para enajenados una terapéutica que pretendía recuperar para la sociedad al loco que se encontraba

${ }^{42}$ Ibidem, vol. 8, sesión del 23 de agosto de 1921, fj. 262. Sievers, 2013: 131-136. 
en la irracionalidad. De ahí que la preocupación estatal se concentrase en las instituciones para enajenados curables.

Sin embargo, el panorama fue más complejo y es aquí donde los representantes locales del Estado, a través de la Intendencia, muestran una concepción diferente del problema. Estaba claro, de acuerdo con la información proporcionada por la Intendencia y los presupuestos para el área de Beneficencia en la provincia, que el Estado sí demostraba una preocupación en el área de salubridad mental, participando, a través de sus representantes, en la creación, remodelación y financiamiento de dichos establecimientos. De hecho, el manicomio de Concepción se encontraba dentro de las instituciones que recibían mayor aporte financiero estatal, aparte del hecho de que la Junta de Beneficencia de la ciudad solicitó en varias oportunidades, en el período en estudio, una mayor participación estatal en el financiamiento de las instituciones de salud en general, buscando así que el Estado tomase nuevas atribuciones ${ }^{43}$.

El inconveniente radicaba en que cuando el Estado demostraba preocupación por un área, o una parte muy específica de ella, lo hacía imponiendo criterios que no guardaban consonancia con las prioridades o problemáticas de la realidad local. Por ejemplo, en el caso que revisamos, hemos dicho que desde Santiago se mantenía la idea de que el manicomio en Concepción sólo se dedicara a albergar a los enfermos crónicos, pero a nivel local, cuya voz se hace explícita desde la Intendencia, se enfatizaba el interés por implementar en la ciudad un manicomio que cumpliese funciones terapéuticas, pues se argumentaba que la tarea de acoger a los enfermos mentales crónicos ya era desempeñada por otra institución dependiente de la Beneficencia: el Hospicio. En ese sentido, se puede apreciar cómo la Intendencia no fue una mera reproductora del discurso santiaguino que insistía en desahogar la Casa de Orates mientras se construía el nuevo manicomio nacional. Por tanto, cuando se hacía un aumento presupuestario, éste se debía a las gestiones organizadas desde la administración del manicomio sureño, respaldadas por la Intendencia, cumpliendo esta última la función de puente entre las necesidades regionales y el Gobierno (Sievers: 98). La Intendencia, y la Junta de Beneficencia de la ciudad, veían al manicomio como algo permanente y no provisorio, carácter que sólo se daba a las instalaciones, pues estaba claro que en algún momento serían insuficientes. En 1898 ya se indicaba en una comunicación de la Intendencia que el Gobierno tenía «el proyecto de ceder la Quinta de Agricultura para establecer el Manicomio, [pues] sería inútil emprender aquí modificaciones muy costosas ${ }^{44}$.

\footnotetext{
${ }^{43}$ Ibidem, vols. 7 y 8.

${ }^{44}$ ANCh, Intendencia de Concepción, vol. 988, Concepción, 19 de febrero de 1898, fj. 118.
} 
Si se revisan las discusiones y peticiones presupuestarias, se aprecia igualmente la constante solicitud de fondos al Estado, pues la junta de Beneficencia de Concepción consideraba que el único modo de superar la mala situación de los establecimientos a su cargo era aumentando el aporte estatal, el cual por lo demás no era menor, pues en 1901 fue de un 46,4\% ${ }^{45}$. Pero específicamente para el manicomio de la ciudad, los problemas presupuestarios se veían incrementados, ya que sus recursos provenían también del fisco y en menor medida de las erogaciones particulares administradas por la Junta. En 1920, los directivos de esta institución llegarían a expresar que:

...debe tenerse presente que el Manicomio es el más fiscal de los establecimientos de la Beneficencia i por lo tanto, es el que con más razón puede obtener beneficios del fisco, cosa difícil para los otros establecimientos ${ }^{46}$.

El aumento presupuestario para el manicomio se hizo evidente a partir de 1910 y se proyectó hasta 1924 , pues durante tal período recibió la suma permanente de 100.000 pesos. Con tal criterio, se puede apreciar que finalmente el manicomio sureño empezó a ser considerado desde Santiago como una institución permanente y no provisoria ${ }^{47}$.

Desde temprano, tanto la Intendencia como la Junta de Beneficencia consideraron que el manicomio debía promover las funciones terapéuticas por sobre las de asistencia y resguardo de crónicos. Ya a fines del siglo XIX se pensó en un tratamiento sostenido de los pacientes a través de las actividades agrícolas (ergoterapia), que eran reconocidas como una importante fuente de recuperación, influyendo en dicha concepción el determinismo ambiental que atribuía al ambiente (incluyendo a la arquitectura) la definición de conductas que podían llegar a provocar enfermedades. Por ello, higienistas, urbanistas y publicistas de la reforma social y moral de la población, sostenían que los ambientes degradados de las ciudades eran los que producían individuos degenerados $^{48}$. El manicomio, así como lo veía la Intendencia, debía entonces ser algo más que una suerte de cárcel para dementes o un simple asilo: «Todo manicomio debe ser a la vez un hospital destinado al tratamiento de los enajenados, un refujio para los locos incurables; una casa de educación moral y fisica: una escuela primaria, artística, científica i relijiosa; un establecimiento industrial i también hortícola-agrícola; un lugar de aislamiento de seguridad $i$

${ }^{45}$ UDEC, SCh, Junta de Beneficencia de Concepción, vols. 4 y 5.

46 Ibidem, vol. 8, fjs. 105-106.

47 ANCh, Intendencia de Concepción, vol. 1859, Concepción, 5 de noviembre de 1924, sf.

48 Yanni, 2007: 8. 
preservación ${ }^{49}$. Pero en no pocas oportunidades las precariedades económicas o la desorganización administrativa postergaron estas ideas.

El manicomio, en las dos etapas que hemos nombrado, mantuvo su decisión de admitir sólo enfermos curables (locos). En una de las primeras sesiones de la Junta de Beneficencia (1897), se volvió a especificar este tema, cuando se anotaba que se «hizo presente la conveniencia de que se pusiese en conocimiento del intendente para que se le enviase una circular a los intendentes i gobernadores para que no manden en lo sucesivo dementes sino locos a este establecimiento ${ }^{50}$. Con posterioridad, el administrador del manicomio para 1923, Benito Binimelis, también lo dejó en claro, al momento de hablar de un enfermo enviado al Manicomio Avello, expresándose que tal enfermo (incurable), «no es para un Manicomio, sino para un Hospicio, que es donde deben ir los dementes, puesto que los Manicomios son solamente para los locos [...] estamos artos de dementes en el establecimiento, señor Intendente, quienes le quitan el lugar que deben ocupar los verdaderos locos para los cuales no hai cabida» ${ }^{51}$.

¿Cuál era el sentido de priorizar a los locos por sobre los dementes? ¿Había alguna idea detrás? Como hemos planteado, detrás de esta institucionalidad se encuentra presente asimismo la noción de peligrosidad atribuida en este caso al loco, que es visto como un potencial peligro social, siendo necesario el resguardo del orden y moral pública por parte de las autoridades. Ello no era extraño en un medio urbano e intelectual en que tanto la justicia como la ciencia médica, en sus diversas acciones, realizaron una suerte de clasificación de las formas asociadas a la marginalidad social, donde los que se encontraban fuera del espacio conocido como normal (seguidores de las reglas y respetuosos del orden institucional y jurídico de la autoridad) pasaban directamente a engrosar las listas de la anormalidad (transgresores de dicho orden), proceso que tuvo como resultado la medicalización de delincuentes, locos y homosexuales; los que terminaron siendo vistos como enfermos mentales o degenerados ${ }^{52}$. A nivel local es posible ver igualmente tal proceso, en la medida que también la peligrosidad se asociaba a los sectores populares y que dentro de ellos los casos de locura o demencia eran visualizados como más frecuentes, ya sea por factores hereditarios o ambientales (alcoholismo y otros vicios).

${ }^{49}$ ANCh, Intendencia de Concepción, vol. 1272, Concepción, 7 de enero de 1910, fj. 20. Con cursiva en el original.

${ }^{50}$ UDEC, SCh, Junta de Beneficencia de Concepción, vol. 3, fj. 402; similares argumentos en Intendencia de Concepción, vol. 1153, Concepción, 19 de junio de 1905, sf.

${ }^{51}$ ANCh, Intendencia de Concepción, vol. 1669, Concepción, 23 de abril de 1923, sf.

${ }^{52}$ Campos, Martínez y Huertas, 2000. 
Los diagnósticos médico-legales realizados en Concepción terminaron reafirmando que estas ideas de peligrosidad, atribuidas al loco, debían ser examinadas y resueltas antes que lamentar situaciones trágicas. Ahí estaba la función preventiva del manicomio. Por ello, se priorizaba la atención de los locos peligrosos que podían atentar contra sus familiares o la sociedad en general. En tal perspectiva, dichos familiares, los vecinos o las personas del entorno social inmediato, terminaban cumpliendo un rol fundamental al participar del proceso de categorización de conductas normales y anormales, donde la peligrosidad era un elemento importante al momento de establecer quién padecía locura. Lo indicado se refleja en casos como el de Manuel Silva Hernández, en 1928, catalogado de epiléptico y caracterizado por sus «impulsos violentos (que) llevan al crimen, al suicidio, al robo o a cualquier otro delito» ${ }^{53}$. Había en varios diagnósticos una asociación inmediata entre el loco y la potencialidad de éste para perpetrar delitos, por ello la construcción de la figura del loco peligroso se basaba en este discurso del miedo y la sospecha.

En tal lógica, se comprende que otras instituciones se encontraran supeditadas al funcionamiento del manicomio, pues al producirse la saturación de éste, hospicios y cuarteles de policía eran ocupados para el resguardo de los locos. De hecho, la policía de seguridad de la ciudad realizaba distintas tareas vinculadas con el manicomio, entre ellas evaluar de manera preliminar, en no pocas oportunidades, la insania para establecer si había locura o no, revisando los antecedentes, carácter y conductas de algunos detenidos ${ }^{54}$; encargándose además del traslado de los locos, de detener la circulación de éstos por la ciudad y de recibir a insanos provenientes de otras provincias ${ }^{55}$. Ello ocurría en función de su facultad preventiva, como se explicita en numerosos documentos ${ }^{56}$.

A pesar de que la locura era entendida como una enfermedad y un peligro social que podía ser curable, ello no impidió que fuese visualizada también como algo nocivo, provocando sentimientos de inseguridad y miedo en una ciudad que terminó generando una suerte de anillo protector en torno al centro de la ciudad y destinando a la periferia de la misma a los establecimientos penales y de beneficencia que recordaban no sólo la existencia de la marginalidad, sino asimismo su peligrosidad, la que debía alejarse de los ciudadanos-

\footnotetext{
de 1928.

54 Ibidem, vol. 1153, Concepción, 12 de diciembre de 1905, sf.

55 Ibidem, vol. 1709, Concepción, 27 de julio de 1924, sf.

${ }^{56}$ Ibidem, vol. 1675, Concepción, 29 de octubre de 1923 y vol. 1393, Memoria del cuerpo de policía correspondiente a 1913, fj. 11.
}

${ }^{3}$ ANCh, Intendencia de Concepción, vol. 1859, fj. 2662, Los Ángeles, 11 de diciembre 
propietarios que se concentraban dentro de las principales cuadras en torno a la Plaza de $\operatorname{Armas}^{57}$. A éstos últimos se les debía proteger y a los primeros vigilar y encerrar, de manera provisoria o permanente, de ser necesario.

De acuerdo con lo expresado, podemos apreciar que en la ciudad de Concepción, comienza a tomar una forma más definida un Estado que participa activamente en el proceso de reforma de los manicomios, situación que hace posible el surgimiento de un poder médico que tendrá como rasgo central la promoción de un discurso modernizador en lo relativo al tratamiento y asistencia de las enfermedades mentales. En dicho escenario, el manicomio de Concepción cumplirá, en sus dos etapas, funciones de defensa social que enlazarán al Estado Guardián-Liberal, por una parte, y al Benefactor-Asistencial, por otra, lo cual se expresará en la vinculación establecida entre instituciones de beneficencia (Hospicio y Manicomio) y de seguridad (Policía); que promoverán una representación social de la locura, entendida como una enfermedad mental y un peligro social. En tal proceso, la Intendencia de Concepción ha marcado una distancia respecto del poder central en Santiago, no por distanciarse de los criterios de defensa social y de atribución de peligrosidad virtual al mundo popular, sino más bien por defender los intereses locales en relación al establecimiento de un manicomio permanente y no provisorio, y por acentuar el carácter terapéutico del recinto por sobre una función de reclusión indefinida.

Vigilar y PRoteger: La función de la tríada Policía, INTENDENCIA Y OFICINA DEL TRABAJO

Los estudios relativos a la institucionalidad policiaca durante el período aquí examinado ${ }^{58}$, han enfatizado los progresos y normales carencias que eran propias de la policía, ya fuese de aseo y ornato o de seguridad, a nivel nacional. Tal panorama es posible encontrarlo también en Concepción y es visible tanto a través de la prensa como de la documentación oficial. Aseveraciones como que la policía de la ciudad «no se distribuye en forma homogénea» o que «no cuenta con el personal necesario, por escasez de dotación, para hacer

\footnotetext{
57 Alarcón y Pedreros, 1989. Hernández y Torres, 1992. Gacitúa y Vergara, 2000. Inostroza y Tapia, 1993.

${ }_{58}$ Hernández Ponce y Salazar, 1994. Peri Fagestrom, 1983. Maldonado, 1996. Miranda Becerra, 1997. Urzúa, 1947.
} 
un servicio completo en toda la ciudad» ${ }^{59}$; son habituales. Misma percepción tuvo la Intendencia en 1917 cuando insistió en que: «El escaso personal con que cuenta es de todo insuficiente para prestar siquiera una mediana vigilancia policial en una ciudad como ésta, que se compone de barrios peligrosos y dilatados, y ubicados algunos de ellos a una considerable distancia del centro de la población» ${ }^{60}$. Impresión que continuará en años posteriores ${ }^{61}$.

A pesar de la precariedad y del escaso interés demostrado entre el peonaje urbano por convertirse en guardianes de seguridad, lo que también es evidenciado por la prensa ${ }^{62}$, en el discurso la policía de seguridad mantenía su rol vigilante y preventivo, protegiendo a los ciudadanos y propietarios de escenas desagradables y peligrosas para su salud física y moral ${ }^{63}$. Esta policía, de acuerdo con los criterios del modelo estatal vigente, era la misma que en razón de la prevención y vigilancia debía llevar un registro de los sirvientes domésticos, de los cocheros de servicio público, de las casas de prostitución, de las tabernas y teatros, aparte de custodiar las calles y controlar los meetings y manifestaciones. Así al menos se había establecido desde su reglamentación en 1896, que había definido una policía de orden, a cargo del aseo y el tránsito, y otra de seguridad, cuya función era encargarse de los crímenes y delitos. Por ende, las funciones de orden, seguridad e identificación que fueron definiendo al cuerpo policial le entregaron, en teoría, un protagonismo significativo.

Sin embargo, como dijimos, las carencias que marcaban a esta institución llevaban a que el papel asignado a ella y la retórica progresista que la rodeaba no se viesen respaldadas siempre por una acción efectiva. Podemos apreciar que en la ciudad aquí estudiada, más que la policía, fueron la Intendencia y una institución reciente, la Oficina del Trabajo, creada en 1907 en Santiago y con una Inspección Regional en Concepción desde 1921, las que en rigor terminaron coordinando y desempeñando una labor de vigilancia, prevención y protección de los intereses de la ciudadanía y de los trabajadores. Por ello, la policía tendrá una función un auxiliar en esta tarea, más que un protagonismo central.

Diversas reformas buscarán terminar con una policía fiscal y municipal visualizada como dependiente y obediente de los intereses locales, según había quedado establecido en 1891 con la denominada ley de comuna autónoma,

59 El Sur, Concepción, 5 de junio de 1900 y 13 de septiembre de 1914. Archivo Histórico de la Municipalidad de Concepción (AHMC), Intendencia y policía de seguridad. vol. 120, 1905.

${ }^{60}$ ANCh, Intendencia de Concepción, vol. 1487, Concepción, 6 de abril de 1917, sf.

${ }^{61}$ El Sur, Concepción, 11 y 14 de mayo de 1920.

${ }^{62}$ El Sur, Concepción, 5 de junio de 1900, 15 de agosto de 1905, 30 de julio de 1911 y 14 de mayo de 1920.

${ }^{63}$ Código de policía local..., 1915: 7. 
aunque se olvidaba que en las ciudades más importantes para inicios del siglo XX: Santiago, Valparaíso y Concepción; ello no era tan así, pues después de 1896 dichos cuerpos policiales habían quedado bajo las órdenes de los respectivos intendentes. Así y todo, se continuará sosteniendo que a nivel general dichas policías no tenían

...instrucción militar ni policial alguna; [pues] no gozaban de remuneraciones fijas, ni tenían uniformidad en su vestimenta ni procedimientos [...] sus remuneraciones se las cancelaban los propios comerciantes de la localidad o personas más connotadas por carencias de fondos en la Municipalidad, incidiendo aquello en su grado de dependencia y de parcialidad en sus actuaciones ${ }^{64}$.

Tal panorama puede encontrar matices, pero en términos generales el poder estatal y sus representantes visualizaban que la función policial, un tema no menor en un período donde la criminalidad y el malestar social aumentaban las alarmas de la peligrosidad no sólo latente, sino evidente, de los sectores populares; debía estar en manos más eficientes. Durante el período examinado, es posible apreciar que a pesar de los inconvenientes, la policía de seguridad continúa desarrollando esta labor de vigilancia e individualización previamente definida que trae beneficios para la Intendencia al momento de identificar a la posible población delincuente. Después de 1927, cuando la policía unificada y centralizada desde 1924 (Policía Fiscal) tome el nombre de Carabineros de Chile, los criterios de individualización e identificación de la población virtualmente peligrosa, se manifestarán más claramente. Ello ocurrirá, por citar un ejemplo, cuando se registre el domicilio de niños indigentes y sus padres en sectores de la cuarta y quinta comisaría de Concepción en 1933, acentuándose éstas y otras identificaciones grupales en los años siguientes ${ }^{65}$.

Por otra parte, si se revisan las informaciones recopiladas a través de la Oficina del Trabajo, se aprecian no sólo referencias frecuentes a las condiciones de vida y trabajo de los sectores populares a lo largo y ancho del país, sino también una estadística cada vez más pormenorizada respecto del número de huelgas y acciones atentatorias al orden interno. De hecho, cuando se creó la Inspección Regional en 1921, ésta fue instalada en la misma Intendencia, con una función bastante clara, la de servir «de intermediario procurando avenimiento amistoso y soluciones de justicia en los conflictos que se suscitan entre patrones y obreros», especificándose además que

\footnotetext{
${ }^{64}$ Peri Fagestrom, 1983: 201.

${ }^{65}$ AHMC, Intendencia y oficinas públicas, 1933, Informes del 26 y 28 de julio de 1933.
} 
...en lo sucesivo toda reclamación que tengan que hacer a sus patrones los gremios o individualmente los obreros de su dependencia, deberán ponerla en conocimiento de esta inspección antes de dar paso alguno que pueda entorpecer la continuación de las labores en que se hallan ocupados. Si las diligencias que pueda hacer esta Oficina no dieran resultado, le quedaría, aún el recurso de solicitar la cooperación del señor Intendente de la Provincia o de los Gobernadores respectivos y, posteriormente, la del señor Ministro de Industrias y, en todo caso, la de S. E. el Presidente de la República ${ }^{66}$.

Pero junto con mostrar una mayor cara intervencionista del Estado en el plano social ${ }^{67}$, la Oficina y su versión regional, desde nuestro punto de vista, también ayudó a delinear acciones hacia el mundo del trabajo en función de que la información recopilada identificaba no sólo las necesidades de artesanos, talabarteros, herreros, hojalateros, etc.; sino además a los miembros de las sociedades de obreros, anotando sus direcciones de funcionamiento y número de socios. Otro tanto ocurría cuando se realizaban catastros, también centralizados en la Oficina, sobre las industrias en la provincia y en la ciudad de Concepción, registrándose su tipo, el número de obreros, la presencia de niños, los montos de los salarios y los días y horas trabajadas ${ }^{68}$. Asimismo, desde 1912 se perfeccionan las estadísticas respecto del número de habitaciones obreras, o conventillos en concreto, registrándose detalles relevantes como el nombre del dueño, número de piezas, de ocupantes, la presencia de mujeres y niños y los costos de arriendo ${ }^{69}$.

Lo más significativo en esta línea, es la estadística llevada por la Oficina sobre las huelgas y lockouts (cierre patronal dirigido contra los trabajadores), que detalla la localidad donde éstas se llevan a cabo, la profesión o industria de los huelguistas, las pérdidas y las peticiones de los mismos, la duración del conflicto, las ofertas de los patrones, el número de huelguistas y sus resultados. Desde 1911 hasta 1920 se encuentra una cantidad significativa de dichos reportes ${ }^{70}$. En los años siguientes, los informes de la Inspección Regional también entregan información ambivalente, es decir, que puede servir tanto para monitorear mejor las acciones de los obreros y sus asociaciones, como para canalizar mejor la ayuda a sus necesidades vitales y laborales más básicas. De este modo, pueden también interpretarse los detalles remitidos a

\footnotetext{
${ }^{66}$ Archivo Nacional de la Administración, Santiago de Chile (ARNAD), Dirección General del Trabajo, vol. 71, Concepción, 16 de mayo de 1921.

67 Yáñez, 2008.

${ }_{68}$ ARNAD, Dirección General del Trabajo, vols. 1 y 4.

${ }^{69}$ Ibidem, vols. 20 y 38 con abundante información sobre Concepción.

${ }^{70}$ Ibidem, vols. 16 y 56.
} 
Santiago, desde la Inspección de Concepción, sobre diferentes movimientos huelguísticos, como el ocurrido en Talcahuano, en noviembre de 1918, o en Curanilahue, en mayo de 1921; sobre la visita a 58 conventillos en la ciudad de Concepción, en octubre de 1924; y sobre un homenaje a Luis Emilio Recabarren en Concepción y las localidades cercanas de Coronel, Lota, $\mathrm{Cu}$ ranilahue y Talcahuano, en diciembre también de 1924; sólo por citar algunos de numerosos ejemplos ${ }^{71}$.

Si bien esta preocupación hacia el mundo social era efectiva, pues ayudaba progresivamente a moderar la tensión entre la igualdad jurídica y la desigualdad social y económica, ello no impedía que el Estado pudiese combinar integración, prevención y represión, sobre todo con el movimiento obrero o con quienes esgrimían un discurso similar. Así se explica que desde la Intendencia y la policía se pudiese reprimir, desde la Oficina auxiliar y desde el Gobierno central asumir a la vez una política de conciliación y arbitraje entre el capital y el trabajo, como aconteció por un decreto en 1917. La información recopilada y centralizada por la Oficina, que después pasaría a llamarse Dirección General del Trabajo, también refleja lo expresado, pues junto a narraciones al parecer inofensivas, se establecía una primera línea de identificación de grupos que podían perturbar el orden interno, en especial en fechas sensibles como Navidad, tal como se indicaba en 1924:

En Concepción se organizaron en mítin el día viernes 19 en la noche, en la plaza Independencia, como a las nueve y media los elementos que podríamos llamar "comunistas" y "federados", pues el número total no alcanzaría a 500 personas, contando a todos los que se reúnen por adhesión o simple curiosidad ${ }^{72}$.

Referencias como ésta, con diferentes intencionalidades (preventivas, represivas y hasta asistenciales), abundan a lo largo del período aquí revisado.

La necesidad de ir definiendo mejor el mundo social y obrero que se volvía cada vez más presente para autoridades nacionales y locales, hizo que también hubiese voces críticas dentro de los grupos acomodados y que la cuestión social dejase de ser sólo un diagnóstico para convertirse en una acción concreta visible en leyes e instituciones de carácter social ${ }^{73}$. Ello es conocido, pero lo que no siempre se recuerda con suficiente claridad es que a pesar de los logros del período (desde la citada ley de habitaciones obreras, pasando por la ley de accidentes del trabajo (1916) hasta el decreto de conciliación y

\footnotetext{
71 Ibidem, vols. 44, 96 y 101.

72 Ibidem, vol. 96, 26 de diciembre de 1924.

73 Poblete y Álvarez, 1924.
} 
arbitraje en 1917; para después integrarse el contrato de trabajo y los derechos de seguridad social, activados más bien por la presión de los militares), parece no haberse alterado, en esencia, la visión que la élite (social, profesional, intelectual), tenía respecto de la naturaleza degenerada de los sectores populares. Dicha percepción, encuentra asidero en nuestra ciudad en estudio.

Las transformaciones urbanas y sociales experimentadas en Concepción, y que sobrepasaban las definiciones discursivas, hicieron pronto evidente que la pobreza en la ciudad se volvía más compleja y se redefinía ahora en función del trabajo y el salario ${ }^{74}$. Esta realidad, parte de una «cuestión social» que era propia de las sociedades industrializadas, o en vías de serlo, afectaba las percepciones de las autoridades y la intelectualidad de entonces y se integraba al discurso de la peligrosidad, aunque incorporándose algunos matices. En la medida que el trabajo (físico) se concebía como el «único patrimonio del pueblo», se insistía en su carácter regenerador frente a malas costumbres y vicios como la violencia cotidiana y el alcoholismo, entre otros. Por ende, el obrero (hombre o mujer), aunque pobre, era dignificado por su trabajo, que le entregaba asimismo disciplina, sentido de obediencia y autocontrol ${ }^{75}$; cualidades que le hacían ver menos peligroso. Por ello, se comprenderá, las manifestaciones de trabajadores fueron vistas, desde un comienzo, como una muestra fehaciente de que sin control laboral, nuevamente aparecía el germen de la peligrosidad en dichos grupos. De ahí los énfasis tutelares y policiales para tratar de resolver las tensiones generadas por la miseria y la escasa preocupación hacia el mundo laboral y social como se ha dicho.

La asociación entre pobre, obrero y criminal se refuerza, en especial porque esta tríada simplificadora encuentra asidero no sólo en la mente de autoridades e intelectuales, sino también en espacios concretos como las periferias urbanas. No por nada, en dichos sectores de la ciudad se había establecido que acechaba el miedo y la inseguridad, como también era allí donde vivía mayoritariamente la población popular y se emplazaban instituciones de vigilancia, preventivas y de encierro. Tal sensación de inseguridad, reforzada en el discurso y en las instituciones allí existentes, llevaba a muchos particulares a solicitar permisos para defenderse frente a potenciales agresiones. En la Intendencia de Concepción, por ejemplo, encontramos a un médico cirujano que en 1923 solicitaba autorización para portar armas, pues en sus palabras:

...tengo muchas veces que atender a los enfermos que necesitan la atención médica en sus hogares, ubicados, muchas veces, en barrios apartados del centro de la ciudad,

\footnotetext{
74 Boletín de la Oficina del Trabajo, Concepción, 1911: 2-21; 1915: 111-116.

${ }^{75}$ Huertas, 2009. Nievas, 1999.
} 
en donde somos o, por lo menos, podemos ser víctimas de asechanzas de gente que viven con lo que le producen sus actos delictivos, y como en ocasiones de tal naturaleza, se impone como medio único para salvaguardarnos el llevar consigo un revolver, para repeler las agresiones de la gente maleante ${ }^{76}$.

En años posteriores, el prejuicio se mantendría, como lo confirman no sólo nuevas peticiones a la Intendencia, sino además las opiniones de diversas autoridades ${ }^{77}$.

En este apartado, hemos buscado mostrar cómo dentro del modelo estatal vigente, el de Defensa Social, las labores de vigilancia y protección fueron desarrolladas e implementadas por las tres instituciones aquí aludidas: Policía, Intendencia y Oficina del Trabajo; las cuales funcionaron en distintos niveles $y$, por supuesto, con diferentes protagonismos. Tal situación acontece porque la policía por sí misma, como se dijo, debido a carencias de todo tipo, no podía asumir ni liderar por completo la tarea. Esto no sólo permite caracterizar la presencia de los criterios estatales del período en Concepción, sino además diferenciar a esta realidad local de la caracterización general establecida por Fernández y Tuozzo donde la labor de la policía es central. Asimismo, la información recopilada sobre el mundo popular a través de la Intendencia y de la Oficina, puede interpretarse tanto como un avance del Estado en el intervencionismo social, o también como una manera menos invasiva y explícita de identificar a individuos y grupos, vigilando posibles conductas transgresoras de los obreros y protegiendo a los propietarios, e incluso a los mismos trabajadores, de situaciones abusivas y conflictivas de una $\mathrm{u}$ otra parte. Lo indicado toma sentido si se tiene presente que en las percepciones de la autoridad municipal y estatal, se comprueba que junto a una preocupación por el tema social coexisten actitudes y prejuicios respecto de la virtual peligrosidad de los trabajadores, por sus inclinaciones a ideologías foráneas y a la violencia.

\section{Conclusiones}

A lo largo de nuestra investigación hemos buscado pensar al Estado desde una perspectiva regional, abandonando la impronta centralista y hegemónica respecto de su construcción, con el propósito de rescatar las diversas realidades locales que también ayudaron a definir maneras distintas o complementarias de entender el poder estatal, la ciudadanía y su relación con la

\footnotetext{
${ }^{76}$ ANCh, Intendencia de Concepción, vol. 1873, Concepción, 7 de noviembre de 1923, sf.

77 Ibidem, vols. 1859, 1873 y 1906.
} 
sociedad civil-popular. La historiografía del Estado, desde el siglo XIX en adelante, no entregó mayor atención a lo heterogéneo y buscó simplificar y homogenizar procesos, acciones y normativas, descuidando no sólo problematizar las historias locales para vincularlas a procesos mayores, sino además generalizando hitos y periodizaciones al resto de Chile, entendiendo que los ritmos de la capital (Santiago) eran los mismos ritmos del resto del territorio nacional. Frente a ello, nuestra investigación ha buscado superar en el período de cambio de siglo (1891-1930), el normal esquema que lo concibe como una etapa donde desaparece un modelo de Estado y aparece otro; evidenciando no sólo la necesidad de matizar tal aseveración, sino también de comprender ritmos y formas distintas de concebir al gobierno central desde el gobierno regional. Por ello, frente a la búsqueda de una intervención estatal en materias sociales desde inicios del siglo XX, presente en algunas investigaciones locales, demandándose un protagonismo que el Estado aún no tiene o no quiere tener; proponemos más bien una caracterización de un modelo estatal que puede leerse o interpretarse como una transición desde una naturaleza de corte liberal-guardián a una benefactora-asistencialista. Nos referimos al Estado de Defensa Social o Policial, concebido a partir de necesidades de vigilancia y protección de la ciudadanía, hasta entonces definida y reguardada, en su carácter excluyente, por la legislación. Se trata de una caracterización que visualiza a un enemigo cercano e interno que convive con los ciudadanos y propietarios dentro de las mismas ciudades. Tal enemigo, temido la mayoría de las veces por su virtual peligrosidad más que por acciones concretas, es el mundo popular que habita en las periferias urbanas y que por su naturaleza violenta, requiere ser identificado, vigilado y controlado.

Es precisamente en este escenario histórico y regional, como es el caso abordado de la ciudad de Concepción, desde donde podemos ir más allá de las caracterizaciones establecidas por la historiografía social sobre el período, que no desmerecemos, dado que en la zona en estudio sí vemos una presencia estatal, pero no a través de una política social prematura, que se irá concretando a medida que avancen las primeras décadas del siglo XX, sino por medio de una serie de medidas encaminadas al control preventivo de dichos sectores populares y que documentalmente son visibles a través de áreas muy concretas como la salubridad mental y el respaldo a la pervivencia y consolidación del manicomio en Concepción, como también a través de la fiscalización que se realiza de los trabajadores mediante la vigilancia policial, la supervisión de la Intendencia y los informes de la Oficina del Trabajo y de su Inspección Regional desde 1921. Es allí donde aparece el Estado, más que en iniciativas claras y concretas respecto de las áreas que tradicionalmente se adjudican a la preocupación de un Estado Benefactor o Asistencial: Salud, Educación 
y Vivienda. Y es en todo este proceso donde estimamos que la Intendencia cumple un papel relevante, como puente entre las necesidades locales y el gobierno central, función que merece, sin duda, mayores estudios en el futuro.

Tenemos claro, asimismo, los límites de este Estado de Defensa Social o Policial que las investigaciones consolidan en 1924 con la centralización de las policías y la aparición de la obligatoriedad de la libreta de identificación a nivel nacional. Sabemos que en muchos aspectos el discurso estuvo por sobre una acción efectiva, como ocurría con la policía de Concepción, según vimos, pero no es menos cierto que los principales criterios de control, identificación, vigilancia y protección encuentran asidero en esta realidad local, a través de las fuentes y percepciones de los contemporáneos. Lo que es más, puede apreciarse que avanzada la década de 1920 ideas represivas, preventivas y asistenciales muchas veces se entrelazaron. Tampoco es menos cierto que el denominado Estado de Bienestar fue concebido desde la necesidad de la centralización (ello lo deja en claro la legislación e institucionalidad de carácter social), por lo cual su desarrollo y proyección en los años siguientes impuso y presupuso un modelo previo que demandase la vigilancia y prevención respecto de ese mundo popular que, de tanto ser fiscalizado, terminó imponiéndose como una realidad que debía ser no sólo controlada, sino además incorporada a las decisiones políticas y económicas, más aún en un contexto de cuestión social que no sólo les recordó a muchos la existencia de la pobreza urbana y proletaria, sino además que ésta también podía movilizarse y amenazar la seguridad y propiedad de quienes hasta entonces no habían asumido su real presencia.

\section{BiBLIOGRAFÍA}

Alarcón, Hernán y Pedreros, Pedro, Expansión urbana y condiciones de vida de los sectores populares en la ciudad de Concepción, 1890-1930, Concepción, tesis Universidad de Concepción, 1989.

Aqueveque, Luis A., Consideraciones acerca de los sistemas carcelarios, Concepción, Imprenta Chile, 1920.

Barros, Luis y Vergara, Ximena, "Los grandes rasgos de la evolución del Estado en Chile, 1820-1925", Raúl Atria y Matías Tagle, Estado y política en Chile. Ensayo sobre las bases sociales del desarrollo político chileno, Santiago de Chile, CPU, 1991: 81-124.

Benedetti, Laura, La cuestión social en Concepción y los centros mineros de Coronel y Lota (1885-1910), Concepción, Ediciones Al aire libro, 2011. 
Benítez, Luis E., Las conclusiones de la moderna criminología y la represión en Chile, Concepción, Imprenta Soulodre, 1919.

Bravo Lira, Bernardino, "La crisis de la idea de Estado en Chile durante el siglo XX", Politica, vol. 5, Santiago de Chile, Instituto de Ciencia Política de la Universidad de Chile, 1984: 9-42.

Bravo Lira, Bernardino, De Portales a Pinochet, Santiago de Chile, Editorial Andrés Bello-Editorial Jurídica de Chile, 1985.

Bustos Ramírez, Juan, "Estado y control: La ideología del control y el control de la ideología", Roberto Bergalli y Juan B. Ramírez, El pensamiento criminológico II, Barcelona, Editorial Península, 1983: 11-35.

Campos Marín, Ricardo, Martínez Pérez, José y Huertas, Rafael, Los ilegales de la naturaleza. Medicina y degeneracionismo en la España de la Restauración (18761923), Madrid, CSIC, 2000.

Camus, Pablo, "Filantropía, medicina y locura: La Casa de Orates de Santiago, 18521894", Historia, 27 (Santiago de Chile, 1993): 89-140.

Castedo, Leopoldo, Chile: Vida y muerte de la república parlamentaria. (De Balmaceda a Alessandri), Santiago de Chile, Editorial Sudamericana, 1999.

Cavarozzi, Marcelo, "El Estado oligárquico en Chile”, Historia y Sociedad, 19 (México D.F., 1978): 19-48.

Código de Policía local para la comuna de Concepción, Concepción, Imprenta y Litografía V. Soulodre, 1915.

Edwards, Alberto, La Fronda Aristocrática en Chile, Santiago de Chile, Imprenta Nacional, 1928.

Espejo, Carlos A., Los delincuentes menores. Su responsabilidad, medios de control. Concepción, Imprenta Valparaíso, 1915.

Feliú Cruz, Guillermo, La Constitución de 1925 y la Facultad de Ciencias Jurídicas y Sociales, Santiago de Chile, Editorial Jurídica de Chile, 1951.

Fernández, Enrique, Estado y sociedad en Chile, 1891-1931. El Estado excluyente, la lógica estatal oligárquica y la formación de la sociedad, Santiago de Chile, LOM Ediciones, 2003.

Fernández Labbé, Marcos, “Alcoholismo, herencia y degeneración en el discurso médico chileno, 1870-1930”, Rafael Gaune y Martín Lara (eds.), Historias de racismo y discriminación en Chile, Santiago de Chile, Uqbar editores, 2009: 17-40.

Foucault, Michel, La vida de los hombres infames, Buenos Aires, Ediciones Altamira, 2006.

Gacitúa, Gladys y Vergara, Mariana, Salud y educación en Concepción, 1930-1944, Concepción, tesis Universidad de Concepción, 2000. 
Góngora, Mario, Ensayo histórico sobre la noción de Estado en Chile en los siglos XIX y XX, Santiago de Chile, Ediciones La Ciudad, 1981.

Hernández, Hilario, "El Gran Concepción. Desarrollo histórico y estructura urbana. Primera parte", Informaciones Geográficas, 30 (Santiago de Chile, 1983): 47-70.

Hernández, Jorge y Torres, Ada, Sectores populares en Concepción: condiciones de vida y respuesta popular e institucional (1929-1935), Concepción, tesis Universidad de Concepción, 1992.

Hernández Ponce, Roberto y Salazar, Jule, De la policía secreta a la policía científica, Santiago de Chile, Policía de Investigaciones de Chile, 1994.

Huertas, Rafael, "Medicina social, control social y políticas del cuerpo. La subjetivación de la norma", Marisa Miranda y Álvaro Girón (coords.), Cuerpo, biopolítica y control social. América Latina y Europa en los siglos XIX y XX, Buenos Aires, Siglo XXI Editores, 2009: 19-41.

Ibáñez Santa María, Adolfo, “Los «ismos» y la redefinición del Estado. Tecnicismo, planificación y estatismo en Chile, 1920-1940”, Atenea, 474 (Concepción, 1996): 183-216.

Illanes, María Angélica, En el Nombre del Pueblo, del Estado y de la Ciencia (...) Historia social de la Salud Pública. Chile, 1880-1973, Santiago de Chile, Colectivo de Atención Primaria, 1993.

Inostroza, Gina, Realidad de las trabajadoras textiles: condicionantes estructurales y desarrollo de procesos sociopolíticos al interior de las comunas de Concepción, Tomé y el pueblo de Chiguayante, 1930-1952, Concepción, tesis de la Universidad de Concepción, 1999.

Inostroza, Gina y Tapia, Marcela, Mujeres populares penquistas en el trabajo (independientes-asalariadas) y condiciones de vida, 1895-1905, Concepción, tesis Universidad de Concepción, 1993.

Jobet, Julio César, "Movimiento social obrero", Desarrollo de Chile en la primera mitad del siglo $X X$, vol. I., Santiago de Chile, Ediciones de la Universidad de Chile, 1951: 51-106.

Jocelyn-Holt, Alfredo, El peso de la noche. Nuestra frágil fortaleza histórica, Buenos Aires, Ariel, 1997.

León León, Marco Antonio, Encierro y corrección. La configuración de un sistema de prisiones en Chile (1800-1911), 3 vols., Santiago de Chile, Universidad Central de Chile, 2003.

León León, Marco Antonio, Estudios sobre la «Capital del Sur»: Ciudad y sociedad en Concepción, 1835-1930, Concepción, Archivo Histórico de Concepción, 2015.

Mac Clure, Oscar, En los orígenes de las políticas sociales en Chile, 1850-1879, Santiago de Chile, Ediciones Universidad Alberto Hurtado, 2012. 
Maldonado, Carlos, "Militarización de la policía: Una tendencia histórica chilena", Peter Waldmann (ed.), Justicia en la calle. Ensayos sobre la policía en América Latina, Medellín, Konrad Adenauer/ISLA Universitat Augsburg/CIEDLA-Buenos Aires, 1996: 73-97.

Marshall H., Enrique, Los araucanos ante el Derecho Penal, Concepción, Imprenta y Encuadernación Moderna, 1917.

Marshall, T. H. y Bottomore, Tom, Ciudadanía y clase social, Madrid, Alianza Editorial, 1998.

Massardo, Jaime, "Legislación social y clases subalternas. Apuntes para un estudio crítico de la historia de las políticas sociales en Chile", Cuadernos de prácticas sociales, 3, Santiago de Chile, Universidad Arcis, 2004: 29-68.

Mazzei, Leonardo, Sociedades comerciales e industriales de Concepción, 1920-1939, Santiago de Chile, Editorial Universitaria, 1991.

Molina Bustos, Carlos, Institucionalidad sanitaria chilena, 1889-1989, Santiago de Chile, LOM Ediciones, 2010.

Miranda Becerra, Diego, Un siglo de evolución policial de Portales a Ibáñez, Santiago de Chile, Departamento de Estudios Históricos, Instituto Superior de Carabineros, 1997.

Nievas, Flabián, El control social de los cuerpos, Buenos Aires, Eudeba, 1999.

Peri Fagestrom, René, Historia de la función policial en Chile, vol. 3., Santiago de Chile, Imprenta de Carabineros, 1983.

Pinto, Jorge, La formación del Estado y la nación y el pueblo mapuche. De la inclusión a la exclusión, Santiago de Chile, Dibam/Centro Barros Arana, 2003.

Poblete, Moisés y Álvarez, Oscar, Legislación social obrera chilena (Recopilación de leyes y disposiciones vigentes sobre el trabajo y la previsión social), Santiago de Chile, Imprenta Santiago de Chile, 1924.

Salazar, Gabriel, Construcción de Estado en Chile (1760-1860). Democracia de «los pueblos». Militarismo ciudadano. Golpismo democrático, Santiago de Chile, Editorial Sudamericana, 2005.

Salazar, Gabriel y Pinto, Julio, Historia contemporánea de Chile, vol. I., Santiago de Chile, LOM Ediciones, 1999.

Salinas, René, "Salud, ideología y desarrollo social en Chile, 1830-1950”, Cuadernos de Historia, 3 (Santiagode Chile, 1983): 99-126.

Salvatore, Ricardo y Sozzo, Máximo, “Criminología moderna en América Latina y Estados Unidos (1880-1940)", Lucía Dammert (ed.), Crimen e inseguridad. Políticas, temas y problemas en las Américas, Santiago de Chile, FLACSO-Catalonia, 2009: 19-56. 
Sievers, Alexander, Médicos, instituciones y locura en Concepción, 1891-1929, Chillán, tesis para optar al grado de Magíster en Historia de Occidente, Universidad del Bío Bío, 2013.

Tuozzo, Celina, El Estado Policial en Chile, 1924-1931, Buenos Aires, La Crujía ediciones, 2004.

Urzúa Valenzuela, Germán, Evolución de la Administración Pública Chilena (18181968), Santiago de Chile, Editorial Jurídica de Chile, 1970.

Urzúa Valenzuela, Germán y García, Ana María, Diagnóstico de la burocracia chilena (1818-1969), Santiago de Chile, Editorial Jurídica de Chile, 1971.

Urzúa, Waldo, De la pesquisa al investigador. Reseña histórica del desenvolvimiento de los servicios de investigaciones en el país, Santiago de Chile, La Nación, 1947.

Villalobos, Sergio, "Conformación histórica del centralismo", Luz Bulnes et. al., La regionalización, Santiago de Chile, Editorial Jurídica de Chile, 1988: 111-128.

Vivallos, Carlos y Brito, Alejandra, "Los sectores populares ante el proceso modernizador del Gran Concepción (Chile, 1880-1940): Perspectivas de análisis”, Revista de Humanidades, 17-18 (Santiago de Chile, 2008): 51-66.

Yanni, Carla, The Architecture of Madness: Insane Asylum in the United State, Minneapolis, University of Minnesota Press, 2007.

Yáñez, Juan Carlos, La intervención social en Chile, 1907-1932, Santiago de Chile, RIL Editores, 2008.

Fecha de recepción: 28 de febrero de 2014.

Fecha de envío de las modificaciones: 11 de junio de 2014.

Fecha de aceptación: 19 de noviembre de 2014. 


\section{Between defense and social intervention: State, citizenship and poverty in the city of Concepción (Chile, 1890-1930)}

This research seeks to understand the Chilean state from three perspectives: regional, relational and constructive. Taking the specific case of the city of Concepcion in the period between 1890 and 1930), we observe the particularities of a state model that has not yet been properly studied, namely Social Defense, which differs from its nineteenth-century predecessor, the 'Guardian State', and its natural successor, the 'Welfare State'. The features and the policy and institutional manifestations of this model can, we believe, be seen both in the area of mental health and the asylum, and in the complementary role of surveillance and protection adopted by the Administration, Police Security Service and Labor Office.

KEY Words: state; citizenship; poverty; exclusion; social defense; social intervention. 